\title{
The relationship between grading and teacher judgment
}

\author{
Anna Drexlerová, Klára Šed’ová, Martin Sedláček
}

Abstract: This paper presents two studies examining the interrelation of grading and teacher judgment. Study 1 revealed the structure of teacher judgment two teachers and their classes, based on data from long-term ethnographic research. Through inductive analysis of teacher statements about students, four criteria by which teachers judge their students were identified: performance, aptitude, effort, and communicativeness. Using quantitative data from 639 students and 32 teachers, Study 2 explored the relationship between the criteria for teacher judgment identified in Study 1 and the grade assigned to a particular student. Evaluation questionnaires that teachers completed about their students were used. All four criteria identified in Study 1 positively correlated with the grade, but as the multiple linear regression analysis showed, the final grade was most influenced by the category of performance. However, a teacher's perception of a student's performance did not always fully align with their performance as measured by a standardized test.

Keywords: grading, teacher judgment, student performance, effort, communicativeness, aptitude

\section{Introduction}

This paper is concerned with grading in connection with teacher judgment processes. Grading is a significant school phenomenon with potential far-reaching implications for students. Research has shown an interrelation between student grades and student motivation, self-esteem, and selfefficacy (Ross \& Kostuch, 2011; Perry, Davies \& Qiu, 2018). Students form an idea of how successful they are on the basis of the grades they get, which can affect their beliefs about their competencies, their further motivation and effort, and consequently their future achievement. 
The effects attributed to grades are ambiguous. On the one hand, they are believed to support the learning process (Gustafsson \& Erickson, 2013; Südkamp, Praetorius \& Spinath, 2018). On the other hand, some authors draw attention to the negative impact of grading - for example, in promoting unhealthy competitiveness or suppressing motivation and creativity in students (Tomlinson, 2010; Lipnevich \& Smith, 2009).

For teachers, grading students is part of their day-to-day duties. Alm and Colnerud (2015) reported grading as one of the most difficult and least popular teacher duties. As Brookhart et al. (2016) noted, teachers use measures of student performance, primarily tests, as major determinants in grading. At the same time, it is important for teachers to grade fairly, with fairness being understood as considering criteria and sources of information other than performance in the grading process. Tierney (2014) claimed: "Fairness in classroom assessment is a complex quality that relies heavily on teachers' professional judgment." Murillo and Hidalgo (2017) argued that a fair assessment does not mean assessing and grading all students the same way.

It is evident that grading is an activity that involves inner tension for teachers caused by ethical dilemmas (Pope et al., 2009); at the same time, teachers are aware of the importance of grades for students and the influence of grades on student achievement. Therefore, it is relevant to examine what guides teachers in grading, what student characteristics are significant in forming teacher judgments of students, and how this judgment is in turn reflected in teacher grading practices.

\section{Theoretical Background}

\section{Grading}

In the Czech school system, grading is governed by a decree issued by the Ministry of Education, Youth and Sports that stipulates that school grades should reflect in particular the attained level of education of the student with regard to the expected learning outcomes in individual subjects and the educational capacity, personality traits, and age of the student. Grading may also take into account the student's attitude to education and other factors affecting their achievement (Münich \& Protivinský, 2018, p. 5). It can be argued that the assigned grades should primarily reflect the academic performance of the students, but there is also room for teachers to incorporate in the grades the student's overall attitude to school duties.

It is generally accepted that grading is the most common feedback for 
students, giving them and other stakeholders (for example, parents) a brief and summary report on how well they are doing at school (Brookhart, 1994; Lipnevich \& Smith, 2009; Tomlinson, 2010). From this perspective, as McMillan, Myran and Workman (2002) pointed out, grades are perceived as a form of reward provided to students on merit. Empirical research has examined the extent to which grades actually reflect student performance. In these studies, student grades are correlated with the results of standardized knowledge tests. The correlation between the grade and test scores in these studies oscillates between 0.4 and 0.6 (Carter, 1952; Farkas et al., 1990; Brennen et al., 2001; Woodruff \& Ziomek, 2004; Duckworth \& Seligman, 2006; Pattison, Grodsky \& Muller, 2013). It is clear that there is a strong, but not absolute, overlap between the grade and student performance.

Other student characteristics with an impact on grades have been investigated. Carter (1952), as well as McCandless, Roberts, and Starnes (1972), demonstrated a positive association between grades and intelligence as measured by intelligence tests. Farkas et al. (1990) provided evidence that student work habits have a positive impact on their grades. Similar results were presented by Duckworth and Seligman (2006) in relation to student self-discipline and by Kelly (2008) in relation to the degree of their engagement in classwork. Casillas et al. (2012) identified the influence of former academic achievements and discipline. A study by Klapp Lekholm and Cliffordson (2009) showed that grades are influenced by student motivation and self-efficacy (Diaconu-Gherasim et al., 2019).

The relationship between grades, achievement, and gender has been repeatedly demonstrated - girls get better grades on average, although they do not outperform boys on achievement or IQ tests (Carter, 1952; Brennen et al., 2001; Duckworth \& Seligman, 2006). A relationship has also been shown between grades, achievement, and student socio-economic status, with higher socio-economic status correlated with better grades ${ }^{1}$ (Kelly, 2008; Westphal et al., 2016).

In the studies cited, student grades are related to different characteristics of individual students. Although the conclusions and findings are heterogeneous, there is clear agreement that in addition to performance, other student characteristics, including their cognitive and socio-demographic characteristics, as well as the different aspects of their approach to schoolwork, contribute to student grades. The existing research explains the in-

1 Even when accounting for achievement. 
consistency between grades and test scores in that teachers consider other non-performance criteria in their assessments of students.

\section{Teacher judgment}

The studies cited in the previous section conceptualized grades as a result of different student characteristics. A complementary perspective understands grades as being determined by the teachers' judgment.

Teacher judgment can be operationalized as the teacher's estimation of a student's current academic achievement (Zhu, Urhahne \& Rubie-Davies, 2018). As Vanlommel (2018) pointed out, teacher judgment has a rational side that manifests through the teacher's search for and evaluation of different data sources, and an intuitive side based on a quick and not fully conscious thought process. Teacher judgment has far-reaching implications because it serves as the basis for the teacher in assessing the student's work and school performance and in adapting communication with the student (Ready \& Wright, 2011; Urhahne et al., 2011; Urhahne \& Zhu, 2015; Drexlerová, 2018). The teacher's judgment is reflected in how the teacher approaches individual students in the classroom, in what tasks they assign, and in what clues they provide for dealing with these tasks (see Sedova $\&$ Salamounova, 2016). For example, students perceived as outstanding by their teacher may face more difficult questions and tasks and get more sophisticated clues and feedback. At the same time it affects how students are finally assessed and graded. For this reason, teachers should be, according to Walker et al. (2015) experts in assessing the level of students' abilities in terms of academic skills and social behavior. As the authors put it: "There is a long-standing body of research showing that teacher ratings predict important student outcomes, such as academic achievement and peer social status, well into the future" (Walker et al., 2015, p. 365-366).

The way teachers perceive and evaluate their students is consciously or unconsciously reflected in teacher behavior towards individual students. The teacher approaches different students differently, or in other words, acts differentially (Babad, 2005; Bressoux \& Pansu, 2016; Higgins, 2011; Newberry, 2013), for example with preferential behavior towards high-achievers and broadminded behavior towards low-achievers. This has some effect on students. As noted by Bressoux and Pansu (2016), students tend to adopt the teacher's evaluation, internalizing it over time. This perception of oneself and of one's capacities impacts actual academic achievement. Students who are perceived as high achievers by the teacher may consequently do better at school. 
The formation of a teacher's judgment is based on diverse sources of information. Bressoux and Pansu (2016) suggest four main domains of these sources. The socio-demographic characteristics of students, including gender, socio-economic status, and ethnicity ${ }^{2}$ represent the first domain. The second domain that teachers draw on is the school characteristics of students, such as their academic history and general information concerning school life. Further, teachers take into account the physical appearance of students and their classroom behavior, with their main focus on the degree of participation in learning and cooperation. This suggests that it is likely that each teacher attaches different significance to individual factors and thus judges in a specific and unique way.

Kaiser et al. (2013) argued that the accuracy or adequacy of a teacher's judgment is a key component of the teacher's professional skills and abilities. If teachers are able to adequately assess student characteristics such as performance and motivation, they will offer their students the appropriate instructions and feedback that the students need for their learning process. However, teacher judgments are susceptible to errors and inaccuracies (Campbell, 2015; Newberry, 2010; Ready \& Wright, 2011; Urhahne et al., 2011). The most frequently mentioned factors are gender, ethnicity, and the teacher-student relationship. In general, authors have concluded that girls, whites, and students with a close relationship with the teacher tend to be overrated.

\section{How teacher judgment is related to grading}

There is an apparent relationship between the teacher's judgment and grading, since the awarding of a grade is necessarily based on the teacher's assessment of the student. Yet there are few studies in which student grades were explicitly related to the processes involved in teacher judgment. The study by Westphal et al. (2016), which examined the extent to which teachers' assessments of students' classroom behavior and motivation are involved in their grading practices, is an exception. A similar study was undertaken by Gagné and St Père (2002), revealing a strong link between teacher judgments of student motivation and student grades.

Several studies have questioned the accuracy with which teachers can judge student performance and motivation. Kaiser et al. (2013) found that "teacher judgments of student motivation point to a rather low level of agree-

2 We do not focus on ethnicity in this study, as Czech schools are not very diverse. 
ment between teacher ratings and student self-reports" (Kaiser et al., 2013, p. 74). Another study in this line of research by Urhahne and Zhu (2015) compared teacher judgments of students' subjective well-being with selfreports of students. The teachers were able to evaluate positive student feelings more accurately than negative ones. The implicit message of these studies is that if teachers were able to judge their students accurately, it would lead to greater student satisfaction at school, as well as higher selfesteem and self-efficacy, factors that undoubtedly have an impact on student performance and on their grades.

Nevertheless, teacher approaches to the grading process are fluid because teachers are aware of the importance and effect of grades on students. Although assessment experts claim that grades should reflect primarily the performance or the degree of fulfilment of a particular assignment (Green et al., 2007; Randall \& Engelhard, 2010), actual teacher practice is different. A number of authors have examined teacher statements about their grading practices.

The findings suggest that teachers knowingly consider, in addition to student performance, a range of other aspects of student work in their grading. McMillan (2001) argued that teachers mainly try to assign grades that reflect fairly both the performance and the effort students make. Randall and Engelhard (2010) added to these aspects students' abilities or potential and their classroom behavior. According to McMillan, Myran, and Workman (2002), student participation, in terms of active involvement in learning and doing extra work, also plays a role in teachers' grading practices. Ross and Kostuch (2011) further mentioned the process of comparison with other students and with the overall school achievement rating. Student grades thus may reflect teacher evaluations of fairly diverse aspects of student attitudes to schoolwork.

Many authors have noted that despite attempts to systematize and objectify the grading process, the basic characteristic of this procedure is that it is a highly individualized practice for teachers. The grading method reflects the teacher's own educational philosophy, values, personal and professional characteristics such as gender or status in the educational institution hierarchy, and other socio-cultural factors (Biberman-Shaley et al., 2011; McMillan, 2001; McMillan, Myran \& Workman, 2002; Randall \& Engelhard, 2010). As a result, the grading method is often unique and teacher-specific. As Green et al. (2007) noted, requiring fairness, usefulness, accuracy, and ethics of the feedback provided by teachers to students can serve as a potentially unifying element. 
These studies have suggested that teachers use various guides when grading. Although there have been multiple studies dealing with this topic, they tend to look either at the views of the teachers on evaluation or at what grades are received by particular types of students. Research linking the perspectives of teachers and the actual impact on students in the form of grades is missing. This paper is, therefore, written with a view to establishing this link.

\section{Aims of the Present Work}

In this article, we aim to explore the relationship between teacher's judgment and grading. In other words, we explore how teachers think about students and how their judgment about their students is reflected in the students' school assessment.

The paper involves two studies. The first study uses data from the longterm ethnographic research of two teachers and their classes to expose the structure of teacher judgment. In this study, we identify the criteria teachers use when evaluating individual students.

The second study, using quantitative data from 639 students and 32 teachers, shows the relationship between the individual criteria of a teacher's judgment of a particular student and the grade that the teacher gives to that student.

We asked the following research questions:

1. What criteria are used by teachers to orient their judgment of individual students? (Study 1)

2. How is the teacher's judgment about individual students related to the grade that the students get from this teacher? (Study 2)

\section{Study 1}

Methods

Study 1 was carried out as a longitudinal, ethnographic, multiple case study. This involved intensive year-round field research that combined multiple methods of data collection - structured and unstructured lesson observations, audio recordings of lessons, semi-structured interviews with teachers, and interviews with students. The research was conducted in two classes during the 2015/2016 school year (CLASS A) and the 2016/2017 
school year (CLASS B). All of the classes were sixth grade, which is the first grade of lower secondary school in the Czech Republic. In this grade, students meet for the first time with teachers who will then teach them for the next four years (sixth grade to ninth grade). The aim of the ethnographic study was to examine how the teacher's judgment of students is shaped in the course of the school year.

CLASS A consisted of 21 students - 11 girls and 10 boys. The participating teacher taught in the given class Czech language arts in the scope for 5 $\times 45$ minutes per week. The teacher was a woman with more than 30 years of experience. CLASS B consisted of 27 students -15 girls and 12 boys. The participating teacher taught in the given class mathematics in the scope for $4 \times 45$ minutes per week. The teacher was also a woman with more than 30 years of experience. Both classes were located in the same school: a medium-sized school in the center of a large city attended predominantly by middle-class and working-class students.

Both classes were observed by the researcher (the first author of this paper) to collect data throughout the school year. For her research, the researcher obtained the informed consent of school management, teachers, and the parents of the participating students. All data used were anonymized.

This study uses data from repeated in-depth interviews with teachers. The interview design contained two areas of questioning. The first area aimed at determining the teacher's judgment of the whole class. The second area focused on individual students and the teacher gradually spoke freely about each of them. During the school year, six interviews with identical structures, each approximately one hour, were conducted. They represent a unique data material that allows us to reveal how the teacher perceives the students and how her judgment is gradually formed. The interviews were recorded using a voice recorder and then transcribed into text. Subsequently, an individual sheet was created for each student, where all the statements of the teacher about the student were entered. The analysis was qualitative. It was based on open coding (Corbin \& Strauss, 2015). This is a procedure during which a researcher repeatedly performs a close reading of the data and inductively creates appropriate codes for phenomena reflected in the data. Subsequently, these emergent codes are clustered in several categories (Corbin \& Strauss, 2015). The first author conducted the coding under the supervision of the second author. As a result of the analysis, four key categories were derived from the inductively established codes: aptitude, 
effort, performance, and communicativeness. They are considered to play key roles since they appeared in all student records in both classes and are saturated by several partial codes.

\section{Results}

An analysis of the teachers' statements revealed that teachers form their judgment about students based on four key categories: performance, communicativeness, aptitude, and effort. As evidenced by the teachers' statements, several different assessment elements are reflected in each category.

In forming their judgments within the category of academic performance, teachers took into account the student's school results, represented by grades or test scores, and academic skills, such as preparation of aids, the ability to respond adequately to questions, and the speed of task fulfilment. Teachers also considered the development of student performance in terms of whether their performance improved or deteriorated over time. Family background was used as a secondary clue in explaining student performance.

Teacher attention to academic performance is illustrated in their statements. Teacher A, for example, commented on one of her students: "Well, I have found that Teodor is probably the best Czech language arts student in this class. He reads beautifully, he is good at Czech, I'd say he enjoys Czech, and that's because he is good at it." We can see in the quotation that the teacher drew conclusions about the performance of Teodor (the best Czech language arts student) on the basis of his ability to read fluently (reads beautifully) and knowledge of the Czech language (he is good at Czech). In addition to the student's performance, the teacher emphasized the aspect of interest (he enjoys Czech). However, the student's interest was perceived as secondary; the teacher assumed that it was motivated by the student's doing well in the subject (because he is good at it). The performance category was also perceived in low-achievers by the teacher, as illustrated by following quote: "She raises her hand instantly, but she fails. Magda spoils what she can do." Although the student exhibited activity during the lesson (raises the hand), her performance was perceived as poor by the teacher (she fails, she spoils what she can do).

Similarly, we can identify a performance-oriented perspective in teacher B's statement: "Patrick, well there, I think he is a completely trouble-free A student. He is quiet, he works, he writes nicely. And I think he'll retain his A grade. In his case, it is clear that he comes from an ambitious family. He 
is simply led in this way." In this statement, the performance of the student (he works; he writes nicely) was associated with a high work ethic that leads to diligent work without the need for teacher intervention (absolutely trouble-free). These traits were associated with family characteristics; more precisely, the teacher assumed that these characteristics were cultivated by the family (an ambitious family; he is simply led in this way). The quote further shows that positive development was clearly anticipated (he will retain his A grade).

The second key category involved in teacher judgment is communicativeness, which indicates the way the student communicates, their openness and their willingness to engage in interactions. Within this category, the external expressiveness of the students is emphasized, not only in the sense of activity prompted and appreciated by the teacher. Teachers also consider students who behave in a "naughty" way, shout out, etc. to be communicative. The importance of this category in teacher evaluations is revealed by the following interview excerpts. Teacher A spoke about one of her students: "Petra is a nice, quiet girl. Actually too nice. Too quiet, right? (She says it scornfully, shaking her head.) She does not express herself. One has to push her hard to make her say anything at all." The teacher negatively perceives the unwillingness to communicate because it makes it impossible to establish contact with the student. This perspective can be illustrated by the use of the expression "nice" in a rather pejorative sense (actually too nice). The teacher is expressing the view that Petra does not show disruptive behavior, but she is undesirably passive (does not express herself). The teacher finds it difficult to get such a student to participate (one has to push her hard).

Teacher B commented on another student: "She does not stand out. I just feel like she is ... I would not even recognize her by her voice. But she's smart. She's got the brains. She's doing well. She works quietly, without me having to prompt her all the time." The teacher, again with some regret, comments on the student's lack of communicativeness (she does not stand out; I would not even recognize her by her voice). However, unlike in the previous statement, the teacher does not associate lack of communicativeness with unwillingness to work. On the contrary, there is a clear appreciation of the student's autonomy and independence from the teacher's management (works quietly without me having to prompt her all the time). Although the student avoids direct verbal contact with the teacher, thanks to her aptitude and hard work, she achieves excellent school results (smart; she's got the brains; she's doing well). It is evident that academic performance and communicativeness are, in the eyes of the teachers, independent categories. 
This is also illustrated by the statement: "Rick is a noisy person; being quiet in a lesson would make him sick, I guess. He is smart, but the talkativeness holds him back." In Rick's case, the communicativeness (noisy person; being quiet would make him sick) is so strong that it negatively influences his performance according to the teacher (the talkativeness holds him back).

Another constitutive category contributing to teacher judgment is aptitude. Teachers perceive aptitude as the natural endowment or capacity of the students to comprehend the knowledge and acquire skills in a given subject. Thanks to aptitude, students have an easier path to school success. This category is therefore closely related to the actual student performance. The inadequate aptitude of one student was mentioned by teacher A in an interview: "We had our books open. I was explaining paragraphs, prose, poetry. The kids had to look for a paragraph. Like they had to count them on the reader's page ... there were eight of those paragraphs there. Well, and Laura, she had no chance. I think she does not understand when I speak Czech. Clearly, she is not gifted." The teacher was primarily talking about the performance of Laura, who was unable to complete a simple assignment. The teacher saw this substandard performance as conditioned by the student's abilities (is not gifted), which is a characteristic that the teacher understands as strongly determining achievement (she had no chance).

Teacher B also formed judgments about students' aptitude, as illustrated by the following statement: "Jarmila and Edita are the smartest kids I have there. I think both will go to a multi-year grammar school. They have no competition in the class and are well aware of it. In addition, Jarmila also has logical thinking, and she copes with stressful situations well, which was clear from how she was doing in that math contest." We see an elaborate description of the students' talents (they are the smartest; they have no competition; she has logical thinking). The teacher concludes that the ability of the students determines their current achievements (how she was doing in that math contest), as well as future achievements (they will go to a multi-year grammar school).

The fourth and final key category that teachers consider in forming their judgments is effort. In the teachers' eyes, effort is manifested through preparation at home, doing homework, reviewing the subject matter before a test, and willingness towards and respect for the teacher's requirements. Teacher A talks about one students who does not belong among the successful students: "For Bibiana, the tutoring is a huge help. And it's interesting 
that she's trying hard, that she won't let go of it. She is not doing well, but she won't give up. I was pleasantly surprised by that (nodding with appreciation)." The teacher highly valued Bibiana's effort (she is trying hard), as demonstrated by Bibiana's raising her hand and regularly doing her homework. The teacher perceived this low-achieving student's attendance of organized tutoring to be crucial (the tutoring is a huge help). The student's attendance of tutoring lessons was proof to the teacher of her independent efforts to achieve a better performance, which the teacher highly appreciated (I was pleasantly surprised by that).

Teacher B spoke in a similar way about a different student: "Diana keeps surprising me. I thought that her mental capacity was not so great, but she is in fact aspiring to an A. Like I never thought that she might be as good as this. Nevertheless, it turns out that, yeah, she is able to work. She is really making a lot of effort; she is single-minded." In contrast to the previous quote, in this excerpt the teacher talked about a successful student (she is aspiring to an $A$ ) whose success largely depended on her effort (she is really making a lot of effort; she is single-minded). The teacher showed great appreciation for the effort and an increasing personal respect for the student. Still, she did not seem to consider the effort sufficient to achieve an excellent performance. When the student achieved an excellent performance, the teacher changed her original judgment about the student's lack of aptitude (I thought that her mental capacity was not so great). Obviously, effort, aptitude, and performance are separate categories, but capable of significant mutual impact.

We identified four key categories in teacher judgment: performance, communicativeness, aptitude, and effort. In each of these categories, a positive and a negative pole can be distinguished. This means that, from the teacher's perspective, a student's performance is either good or poor, the student communicates or does not, is gifted or is not, and makes an effort or does not.

Each student can be assigned to a certain position on the imaginary continuum between the poles of the given categories. Teachers commonly combine the four key categories in their judgments. This is illustrated by the following excerpt from an interview with teacher A: "Adam is calm, conscientious, careful. He does not attract attention, he does not speak much, but he is a clever boy. In Czech language arts, he's got good grades and I think that the class ranks him at the top of the class." It is obvious that the teacher perceives the student as excellent in terms of academic performance and out- 
comes (he is a clever boy; he's got good grades; top of the class). On the other hand, in the category of communicativeness, the teacher classifies him as a passive and non-communicative student (calm; does not attract attention; does not speak much). A common element when teachers are making judgments is the principle of student comparison, which allows the teacher to assess the student within the broader perspective of the whole school class (the class takes him as the top of the class).

\section{Study 2}

\section{Methods}

In this study, we relate data on how teachers judge individual students to the grades that the students receive from these teachers. A total of 32 teachers and 639 ninth-grade students of lower secondary school (ISCED 2A) participated in the research. These classes were involved in a reading literacy testing conducted by the Czech School Inspectorate (CSI). The CSI is a key central institution in evaluating the education system in the Czech Republic, distributing and evaluating standardized tests focused on different areas of student learning to measure student achievement in Czech schools. The sample for this study consisted of ninth-grade students (ISCED 2A) who were involved in the CSI's selective reading literacy testing. In this national sample survey, CSI included altogether 163 schools from the total of 4221 Czech lower secondary schools. From this sample, the researchers chose schools from three Czech districts. ${ }^{3}$

We use the results of individual students in reading literacy tests designed and evaluated by the CSI as an indicator of student achievement. Testing took place in November 2017. The test consisted of 16 tasks. An example task is attached in Appendix. The tasks covered all areas of reading literacy that were operationalized in accordance with the curriculum for the grades concerned. In this study, we use the percentage of student success rate in the main section of the test (100\% is the full score).

We sought to identify teacher judgment about individual students. The assessment was made by teachers of Czech language arts, which is a subject that involves reading literacy in the Czech curriculum. Each teacher

3 The Czech Republic is divided into 14 districts. The data were collected in three districts (South Moravian Region, Olomouc Region, and Vysocina Region). We invited to participate in our study all the schools in these three districts that were involved in the CSI testing of reading literacy. 
completed a questionnaire in which they expressed their view about each student as regards the following items:

1. The student has an aptitude for Czech language arts.

2. The student is making an effort and preparing for the lessons.

3. The student has good results in Czech language and arts.

4. The student actively communicates in the class.

These items were created based on the results of Study 1 and represent the individual identified criteria according to which the teachers evaluate their students - aptitude, effort, performance, and communicativeness. Teachers rated students on a four-point scale (1 I agree; 2 I moderately agree; 3 I moderately disagree; 4 I disagree). Teachers completed the questionnaires in November 2017.4

In addition, for each student we also recorded the final grade attained in Czech language arts at the end of the previous school year (June 2017) and in the first quarter of ninth grade (November 2017). In the Czech Republic, students are assessed using a five-point grading scale (1-5), where 1 (A) is excellent, 2 (B) very good, 3 (C) good, 4 (D) satisfactory, 5 (E) fail. If a student is rated at the end of the school year with a grade 5 , that student has to repeat the grade. In this analysis, we only work with the mark from the first quarter of ninth grade, so the grading corresponds to the time in which teacher judgments about their students were collected.

The analytic strategy was as follows. To estimate the impact of teacher judgment and other demographic factors on the student's grade in Czech language arts, we used a multiple linear regression analysis that allowed us to maximize the prediction of the dependent variable with as few as possible relevant independent variables. Because of a higher number of regressors, we apply a modified coefficient of determination (adjusted R2) for interpretation, which in the prediction removes the artificially increased values caused by the number of variables entering the regression analysis.

As far as research ethics are concerned, we first arranged to work with the CSI. They agreed that we could use the reading literacy test results in the research if the schools involved and the parents of the students agreed. We then sought verbal consent from the school principals and all the teachers to allow us to conduct the research in their schools and classrooms. In the

4 When doing so, they were not informed about students' results in CSI tests. 
next step, we sought the written consent of all parents of students participating in the observed classes. Participants were assured of confidentiality and of the ability to withdraw at any time. No-one withdrew. All participants were given numbers; all identifying information was removed from the data before data processing began.

\section{Results}

The aim of the study was to determine the extent to which students' final grades in a subject can be explained by teacher judgments about their students. Before we present the results of our analysis, it seems useful to look at the extent to which school grades are a reflection of factual knowledge and skills. We have the students' results for a standardized reading literacy test that was designed by the CSI and serves as the basis for a comprehensive evaluation of educational results in the Czech Republic. For the students in our sample, the relationship between school grades and the result in this test had a medium value (Pearson $r=-0.42 \mathrm{p}<0.01$ ). It is a significant association in which a better result in the test indicates a better school grade. ${ }^{5}$ A stronger association might have been expected. If we apply the coefficient of determination to such a relationship, we find that the school grade corresponds to standardized test scores only by approximately $20 \%$. However, such an interpretation cannot be taken at face value, because the determination is calculated from a correlation, so causality cannot be determined. Nevertheless, it can be said that schoolteacher evaluation is relatively freely connected to actual achievement and is influenced by other factors.

Since teacher judgments may be listed among these factors, we examined them using further analytical procedures. In addition, we controlled for student gender and socio-economic status ${ }^{6}$, which have in the long term been shown as key intervening variables for both grades and teacher judgments. Table 1 outlines the basic descriptive parameters of all variables entering the models of regression analysis.

5 The negative value of the correlation is due to different scales (the increase in test scores means a better grade, which is actually a drop - that is inverse proportion).

6 Measured as the socio-economic index of occupational status of the family (ISEI). Occupational data for both the student's father and the student's mother were obtained by asking open-ended questions. The responses were coded into four-digit ISCO codes and then recoded to the international socio-economic index of occupational status (ISEI) (Ganzeboom et al., 1992). HISEI corresponds to the higher ISEI score of either parent or to the only available parent's ISEI score. Higher ISEI scores indicate higher levels of occupational status. 
Table 1 Descriptive measures of all variables

\begin{tabular}{|l|c|c|c|}
\hline & N & Mean & Standard deviation \\
\hline performance & 603 & 2.42 & 1.00 \\
\hline communicativeness & 624 & 2.33 & 1.00 \\
\hline aptitude & 624 & 2.48 & 0.97 \\
\hline effort & 623 & 2.23 & 1.04 \\
\hline grades & 635 & 2.61 & 0.97 \\
\hline socio-economic status & 586 & 47.52 & 18.56 \\
\hline
\end{tabular}

All arithmetic means of teacher judgments oscillate around the center of the scale, which corresponds, given that a four-point option was applied, to the value 2.5. Therefore, it can be said, that, across the sample, the students are perceived by their teachers as average. The sample as a whole is not inclined to either extreme in terms of their performance, aptitude, communicativeness, or effort in the subject. Students are seen in the best light by the teachers in terms of effort; aptitude is the worst-rated area. The two-sample t-test shows a statistically significant difference $(p<0.05)$ between boys and girls (Performance: $\mathrm{t}=-6.28, \mathrm{p}<0.01$; Communicativeness: $\mathrm{t}=-6.26, \mathrm{p}<0.01 ;$ Aptitude: $\mathrm{t}=-6.21, \mathrm{p}<0.01 ;$ Effort: $\mathrm{t}=-3.49, \mathrm{p}<0.01$. In all statements, girls got a higher rating. Likewise, girls had better school report grades. Despite the statistical significance, student gender was not a key predictor. For all evaluative judgments, it only accounts for about $2 \%$ of the variability.

If we look at the relationship between teacher judgments and school grades, we find that there are relatively strong associations. The results of the mutual associations, which were, with respect to the scales used ${ }^{7}$, verified by Spearman's rank correlation, are summarized in Table 2.

Looking at each teacher judgment in isolation, student grades were most influenced by the view of the teacher that the student performed well or has good results in the subject $(r=0.81)$. There is also a fairly strong correlation between student grade and teacher conviction about student aptitude $(r=0.79)$. Strong positive links indicate that teachers gave better grades to those students they perceived as more gifted and showing better perfor-

$\overline{7}$ Teacher judgments were measured on an ordinal scale; therefore, we could not use the Pearson correlation. 
Table 2 Values of correlation coefficients (Spearman) between grades and evaluative judgments

\begin{tabular}{|l|c|c|c|c|c|c|}
\hline & grades & $\begin{array}{c}\text { perfor- } \\
\text { mance }\end{array}$ & $\begin{array}{c}\text { communi- } \\
\text { cation }\end{array}$ & aptitude & effort & $\begin{array}{c}\text { socio-econo- } \\
\text { mic status }\end{array}$ \\
\hline grades & 1 & $0.814^{* *}$ & $0.649^{* *}$ & 0.785 & $0.724^{* *}$ & $-0.137^{* *}$ \\
\hline performance & & 1 & $0.701^{* *}$ & $0.830^{* *}$ & $0.767^{* *}$ & $-0.171^{* *}$ \\
\hline communication & & & 1 & $0.684^{* *}$ & $0.682^{* *}$ & $-0.198^{* *}$ \\
\hline aptitude & & & & 1 & $0.686^{* *}$ & $-0.149^{* *}$ \\
\hline effort & & & & & 1 & $-0.191^{* *}$ \\
\hline $\begin{array}{l}\text { socio-economic } \\
\text { status }\end{array}$ & & & & & & 1 \\
\hline
\end{tabular}

Note: * marked correlations are significant at the level of $p<0.05 ;{ }^{* *}$ at the level of $p<0.01$

mance. However, we also identified significant interrelations between grades and the remaining two categories of teacher judgment.

It is evident that teachers do not form their individual judgments about students in isolation. The categories are interdependent. The grade that the student receives from the teacher is ultimately influenced by these links. To estimate the net influence of categories of teacher judgment on final school grades (after the aforementioned intercorrelations have been filtered out) we used multiple linear regression analysis. The linearity of relationships and normal distribution were verified by point distribution and residual analysis. We used SPSS 25 diagnostics to check for apparent or hidden multicollinearity. As shown in Table 3, all coefficients of collinearity (VIF and tolerance) were below the generally accepted critical values, indicating the suitability of regression analysis.

To estimate the best model, we applied the following procedure. The basic model shows to what extent the student grades in our sample are explicable on the basis of the key demographic characteristics of gender and socioeconomic status of their primary family. In further models, we gradually estimated the impact of individual categories of judgments on the grade. We successively added them to the models according to the strength of the interrelationship. The results are summarized in Table 4.

The basic Model 1 built only around the demographic characteristics of the student confirms the assumption that these are significant predictors of school grades. However, gender and socio-economic status are not very strong factors in our sample. As the coefficient of determination (adjusted 
Table 3 Multicollinearity tests

\begin{tabular}{|l|c|c|}
\hline \multirow{2}{*}{} & \multicolumn{2}{|c|}{ Collinearity coefficients } \\
\cline { 2 - 3 } & Tolerance & VIF \\
\hline performance & 0.24 & 4.07 \\
\hline communicativeness & 0.44 & 2.30 \\
\hline aptitude & 0.33 & 3.02 \\
\hline effort & 0.38 & 2.64 \\
\hline sex (male) & 0.88 & 1.13 \\
\hline socio-economic status & 0.96 & 1.04 \\
\hline
\end{tabular}

Table 4 Estimates of student grade models

\begin{tabular}{|l|c|c|c|c|c|c|c|c|c|c|}
\hline & \multicolumn{2}{|c|}{ Model 1 } & \multicolumn{2}{c|}{ Model 2 } & \multicolumn{2}{c|}{ Model 3 } & \multicolumn{2}{c|}{ Model 4 } & \multicolumn{2}{c|}{ Model 5 } \\
\hline & B & $\boldsymbol{\beta}$ & B & $\boldsymbol{\beta}$ & $\mathbf{B}$ & $\boldsymbol{\beta}$ & $\mathbf{B}$ & $\boldsymbol{\beta}$ & $\mathbf{B}$ & $\boldsymbol{\beta}$ \\
\hline constant & 2.31 & & 0.71 & & 0.52 & & 0.49 & & 0.45 & \\
\hline sex (male) & 0.43 & $0.22^{* *}$ & 0.03 & 0.02 & & & & & & \\
\hline $\begin{array}{l}\text { centered socio-eco- } \\
\text { nomic status }\end{array}$ & -0.08 & $-0.09^{*}$ & 0.01 & 0.01 & & & & & & \\
\hline performance & & & 0.78 & $0.81^{* *}$ & 0.50 & $0.52^{* *}$ & 0.37 & $0.39^{* *}$ & 0.36 & $0.37^{* *}$ \\
\hline aptitude & & & & & 0.35 & $0.35^{* *}$ & 0.33 & $0.32^{* *}$ & 0.31 & $0.31^{* *}$ \\
\hline effort & & & & & & & 0.19 & $0.21^{* *}$ & 0.17 & $0.19^{* *}$ \\
\hline $\begin{array}{l}\text { communicative- } \\
\text { ness }\end{array}$ & & & & & & & & & 0.06 & $0.06^{+}$ \\
\hline Adjusted $R^{2}$ & 0.05 & & 0.65 & & 0.69 & & 0.71 & & 0.72 & \\
\hline
\end{tabular}

${ }^{* *} \mathrm{p}<0.01,{ }^{*} \mathrm{p}<0.05,{ }^{+} \mathrm{p}<0.055$

$\mathrm{R}^{2}$ ) shows, together they account for grade variability approximately only by $5 \%$. Surprisingly, a stronger net effect after filtering out the influence of other independent variables was identified for student gender (see column standardized $\beta$ coefficient). With regard to the analysis, a dummy variable was introduced indicating that boys received on average worse grades. If we were to think purely hypothetically and compare boys and girls disregarding

8 To facilitate interpretation, we work with a centered status variable (socioeconomic status will be replaced with centered socio-economic status), the mean of which is zero, since the average value of the original variable is subtracted from all individual values. 
any other characteristics, then it is estimated that a boy would get a grade of about half a grade lower than girls (see the column of non-standardized $\beta$ coefficient). The influence of student socio-economic status was weaker in our sample, although still significant. With an increase in occupational status by approximately ten points, the likelihood of a better grade increased by about one grade. However, our sample was quite homogeneous in terms of the family socio-economic status. The net negative effect of this variable on the school grade therefore appears to be weaker and, as shown below, its influence was completely eliminated in the models that follow.

In Model 2, we added the first category of teacher judgment and belief in good student performance in the given subject. Inclusion of this variable significantly increased the predictive power of modelling a student's final school grades. The model explains as much as $65 \%$ of variability. It is worth noting, however, that the inclusion of teacher judgment nullifies the significance of demographic characteristics. Although we know from previous bivariate analyses that even the teacher's judgment itself is determined by demographic characteristics, we can basically conclude that teacher judgment is a fairly strong predictor of final school grades without any fundamental consideration of the gender and SES of the student.

Model 3 includes, in addition to the previous components, the teacher's judgment about the student's aptitude. Adding this factor increased the proportion of variance explained by $4 \%$ to almost $69 \%$. Hence, the impact of this category of teacher judgment is also significant. This confirms the assumption that from the point of view of the final school grades, the teacher's beliefs about the student's good results $(\beta=0.52)$ is a stronger determinant than the perception of the student's aptitude $(\beta=0.35)$.

In Model 4, we added judgment about the student's effort. Predictive power once again increased; the model explains $71 \%$ of variability. The power of individual categories of judgments naturally decreased; the order of importance remained. The largest proportion of variability of final school grades is explained by the Model 5, which includes the last category of teacher judgment, related to students' communicativeness. The proportion rose by a single unit to the resulting value of $72 \%$.

\section{Discussion}

One of the main conclusions of our study is that student grades are to some extent determined by the teacher's judgment. There are four areas rel- 
evant for the judgment: performance, communicativeness, effort, and aptitude. Our analysis shows that the most important role in relation to grading is played by the teacher's judgment about student's performance. This finding is problematic because teacher judgment is a construct that does not fully align with reality. In other words, the teacher's judgment of the student's performance corresponds to the student's performance on a standardized test to only a limited extent. This means that the teacher's judgment about performance does not represent performance as such, which is evident in that test performance (an alternative and probably more accurate representation of performance) correlates with the grade to a much lesser degree.

The finding that the correlation between grade and actual performance can be described as medium, rather than strong, is in line with the findings of several other studies (Duckworth \& Seligman, 2006; Pattison, Grodsky \& Muller, 2013; Woodruff \& Ziomek, 2004). Previous studies predominantly worked with the assumption that any discrepancy between test scores and grades was because teachers included other non-cognitive criteria, such as effort, ability, or classroom behavior, in the assessment (Keller, 2016; McMillan, 2001; McMillan, Myran \& Workman, 2002; Randall \& Engelhard, 2010). However, our results show that although the teacher primarily considers and evaluates the student performance, this judgment does not align with the test results. Future research, therefore, needs to focus on identifying the constituents of the teacher's opinion about student performance, or the student characteristics and signals that the teacher takes into account when making a judgment about performance. Vanlommel (2018) points out that in addition to the rational aspect of the judgment, which is based on searching for and evaluating relevant data by the teacher, there is an intuitive aspect. The role of intuition in teacher judgment has been insufficiently mapped (Vanlommel, 2018).

Although teacher judgment about student performance plays a dominant role in grading, our results show that other identified categories of teacher judgment - effort, aptitude, and communicativeness - also correlate with grades. Previous research has shown that when teachers consider students to be diligent, they tend to assign better grades to them (Brookhart, 1994; McMillan, 2001; Ross \& Kostuch, 2011). These findings are in agreement with what we have found - the more a student is perceived as hard-working, the better the grade they receive. Our data suggest that judgments about aptitude and communicativeness have a similar effect. Students perceived as gifted and communicative get better grades than students perceived as non-gifted and non-communicative. 
Our analysis also demonstrated that although girls get better grades than boys, this is not primarily due to teachers' making more positive judgments about girls - the relationship between the teacher's judgment and student grades is not influenced by gender. According to Rasooli, Zandi, and DeLuca (2018), this sex bias is not uncommon. The gender perspective of evaluation has been the focus of a number of studies, with authors repeatedly concluding that teachers rate girls higher, thus girls get better grades than boys, although the girls' performances are not better or of a higher quality (Carter, 1952; Brennen et al., 2001; Duckworth \& Seligman, 2006). One possible reason that girls get better grades may be that girls more often possess a feature or characteristic that positively affects the teacher's judgment. A similar line of thought was pursued by Duckworth and Seligman (2006); they observed that girls generally show greater self-discipline, which is more relevant to school report grades than various types of test scores.

A significant number of studies have adopted the perspective of a rather complex relationship between teacher judgment and grading. Kaiser et al. (2013) and Urhahne and Zhu (2015) perceived the evaluation process as a sequence of interdependent elements of teacher judgment and the subjective understanding and processing of this judgment by the students themselves, who are influenced by it in their further performance, which in turn impacts the final grades assigned. Our analyses provided a more straightforward perspective. The teacher makes a judgment about a student and then assigns a grade based on that judgment. We do not question the proposition that teachers, on the basis of their judgment, treat different students differently, thereby further affecting their achievement (cf. Babad, 2005; Bressoux \& Pansu, 2016; Higgins, 2011; Newberry, 2013). However, we believe that grading is a direct manifestation of differentiated behavior, not its consequence. The grade the teacher assigns to the student is a strong indication of how the teacher perceives the student. Strakova and Greger (2013) showed that the educational aspirations of students and their parents are strongly determined by the grades that the students receive from their teachers. This means that grading as an explicit expression of teacher judgment has a direct impact on the student's educational trajectory.

Grades are an important school phenomenon and can have a major impact on students. Grading processes should therefore be a subject of continuous research interest. Our analyses have shown that it is only possible to grasp the mechanisms of grading if we have a solid understanding of the ways teacher judgment is formed. 


\section{Conclusion}

In this paper, we examined how grading and teacher judgment are interrelated. We showed that teachers use four general criteria in their judgment about students - performance, aptitude, effort, and communicativeness. All four criteria have positive and negative poles. The final judgment about a student is determined by a combination of different statuses of the student in each category. All of these categories positively correlate with the grade, but the performance category has the greatest impact on the final grade. The teacher's perception of a student's performance does not fully align with the student's performance as measured by a standardized test. It is therefore necessary for further research to examine in more detail the guides teachers use to make their judgments about student performance

\section{Acknowledgments}

This article is an outcome of the project "On the Relationship between Characteristics of Classroom Discourse and Student Achievement" (GA1703643S) funded by the Czech Science Foundation.

\section{References}

Alm, F., \& Colnerud, G. (2015). Teachers' experiences of unfair grading. Educational Assessment, 20, 132-150.

Babad, E. (2005). Guessing teachers' differential treatment of high- and low-achievers from thin slices of their public lecturing behavior. Journal of Nonverbal Behavior, 29(2), 125-134.

Brennen, R. T., Kim, J., Wenz-Gross, M., \& Siperstein, G. N. (2001). The relative equitability of high-stakes testing versus teacher-assigned grades: An analysis of the Massachusetts Comprehensive Assessment System (MCAS). Harvard Educational Review, 71(2), 173-216.

Bressoux, P., \& Pansu, P. (2016). Pupils' self-perceptions: the role of teachers' judgment controlling for big-fish-little-pond effect. European Journal of Psychology of Education, 31, 341-357.

Brookhart, S. M. (1994). Teachers' grading: Practice and theory. Applied Measurement in Education, 7(4), 279-301.

Brookhart, S. M., Guskey, T. R., Bowers, A. J., McMillan, J. H., Smith, J. K., Smith, L. F., Stevens, M. T., \& Welsh, M. E. (2016). A century of grading research: Meaning and value in the most common educational measure. Review of Educational Research, 86(4), 803-848.

Campbell, T. (2015). Stereotyped at seven? Biases in teacher judgement of pupils' ability and attainment. Journal of Social Policy, 44(3), 517-547.

Carter, R. S. (1952). How invalid are marks assigned by teachers? Journal of Educational Psychology, 43(4), 218-228. 
Casillas, A., Robbins, S., Allen, J., Kuo, Y.-L., Hanson, M. A., \& Schmeiser, C. (2012). Predicting early academic failure in high school from prior academic achievement, psychosocial characteristics, and behavior. Journal of Educational Psychology, 104(2), 407-420.

Corbin, J., \& Strauss, A. (2015). Basics of qualitative research: Techniques and procedures for developing grounded theory. Thousand Oaks, CA, US: Sage Publications, Inc.

Diaconu-Gherasim, L. R., Tepordai, A.-M., Mairean, C., \& Rusu, A. (2018). Intelligence beliefs, goal orientations and children's academic achievement: does the children's gender matter? Educational Studies, 45(1), 95-112.

Drexlerová, A. (2018). Kluků je škoda, holky na to nemají: Genderové aspekty v hodnocení nejslabších žáků třídy. Studia paedagogica, 23(1), 9-28.

Duckworth, A. L., \& Seligman, M. E. P. (2006). Self-discipline gives girls the edge: Gender in self-discipline, grades, and achievement test scores. Journal of Educational Psychology, 98(1), 198-208.

Farkas, G., Grobe, R. P., Sheehan, D., \& Shuan, Y. (1990). Cultural resources and school success: Gender, ethnicity, and poverty groups within an urban school district. American Sociological Reviews, 55(1), 127-142.

Gagné, F., \& St Père, F. (2002). When IQ is controlled, does motivation still predict achievement? Intelligence, 30(1), 71-100.

Green, S. K., Johnson, R. L., Kim, D.-H., \& Pope, N. S. (2007). Ethics in classroom assessment practices: Issues and attitudes. Teaching and Teacher Education, 23(7), 999-1011.

Gustafsson, J.-E., \& Erickson, G. (2013). To trust or not to trust? - teacher marking versus external marking of national tests. Educational Assessment, Evaluation and Accountability, 25(1), 69-87.

Higgins, C. S. (2011). Teacher-student relationship development: A qualitative study of interpersonal connections in an early childhood classroom. PhD diss., The Ohio State University.

Kaiser, J., Retelsdorf, J., Südkamp, A., \& Möller, J. (2013). Achievement and engagement: How student characteristics influence teacher judgments. Learning and Instruction, 28, 73-84.

Keller, T. (2016). Sticky assessment - the impact of teachers' grading standard on pupils' school performance. Educational studies, 42(5), 493-518.

Kelly, S. (2008). What types of students' effort are rewarded with high marks? Sociology of Education, 81(1), 32-52.

Klapp Lekholm, A., \& Cliffordson, C. (2009). Effects of student characteristics on grades in compulsory school. Educational Research and Evaluation, 15, 1-22.

Lipnevich, A. A., \& Smith, J. K. (2009). "I really need feedback to learn:" Student's perspectives on the effectiveness of the differential feedback messages. Educational Assessment, Evaluation and Accountability, 21(4), 347-367.

McCandless, B. R., Roberts, A., \& Starnes, T. (1972). Teachers' marks, achievement test scores, and aptitude relations with respect to social class, race, and sex. Journal of Educational Psychology, 63(2), 153-159.

McMillan, J. H. (2001). Secondary teachers' classroom assessment and grading practices. Educational Measurement: Issue and Practice, 20(1), 20-32. 
McMillan, J. H., Myran, S., \& Workman, D. (2002). Elementary teachers' classroom assessment and grading practices. The Journal of Educational Research, 95(4), 203213.

Münich, D., \& Protivinský, T. (2018). Co skrývají známky na vysvědčení? Národohospodářský ústav AV ČR, studie 1/2018. ISBN 978-80-7344-444-0

Murillo, F. J., \& Hidalgo, N. (2017). Students' conceptions about a fair assessment of their learning. Studies in Educational Evaluation, 53, 10-16.

Newberry, M. (2010). Identified phases in the building and maintaining of positive teacher-student relationships. Teaching and Teacher Education, 26(8), 1695-1703.

Newberry, M. (2013). Reconsidering differential behaviors: Reflection and teacher judgment when forming classroom relationships. Teacher Development, 17(2), 195213.

Pattison, E., Grodsky, E., \& Muller, C. (2013). Is the sky falling? Grade inflation and the signaling power of grades. Educational Researcher, 42(5), 259-265.

Perry, T., Davies, P., \& Qiu, T. (2018). Great grade expectations? The role of pupil expectations in target setting. International Journal of Educational Research, 89, 139-152.

Pope, N., Green, S. K., Johnson, R. L., \& Mitchel, M. (2009). Examining teacher ethical dilemmas in classroom assessment. Teaching and Teacher Education, 25(5), 778-782.

Randall, J., \& Engelhard, G. (2010). Examining the grading practices of teachers. Teaching and Teacher Education, 26(7), 1372-1380.

Rasooli, A., Zandi, H., \& DeLuca, C. (2018). Re-conceptualizing classroom assessment fairness: A systematic meta-ethnography of assessment literature and beyond. Studies in Educational Evaluation, 56, 164-181.

Ready, D. D., \& Wright, D. L. (2011). Accuracy and inaccuracy in teachers' perceptions of young children's cognitive abilities: The Role of Child Background and Classroom Context. American Educational Research Journal, 48(2), 335-360.

Ross, J. A., \& Kostuch, L. (2011). Consistency of report card grades and external assessments in a Canadian province. Educational Assessment, Evaluation and Accountability, 23(2), 159-180.

Sedova, K., \& Salamounova, Z. (2016). Teacher expectancies, teacher behaviour and students' participation in classroom discourse. Journal of Educational Enquiry, 15(1), 44-61.

Straková, J., \& Greger, D. (2013). Faktory ovlivňující přechod žáků 5. ročníků na osmileté gymnasium. Orbis Scholae, 7(3), 73-85.

Südkamp, A., Praetorius, A.-K., \& Spinath, B. (2018). Teachers' judgment accuracy concerning consistent and inconsistent student profiles. Teaching and Teacher Education, 76, 204-213.

Tierney, R. D. (2014). Fairness as a multifaceted quality in classroom assessment. Studies in Educational Evaluation, 43, 55-69.

Tomlinson, C. A. (2010). Grading and differentiation: Paradox or good practice? Theory into Practice, 44(3), 262-269.

Urhahne, D., Chao, S., Florineth, M. L., Luttenberger, S., \& Paechter, M. (2011). Academic self-concept, learning motivation, and test anxiety of the underestimated student. British Journal of Educational Psychology, 81(Pt 1), 161-177. 
Urhahne, D., \& Zhu, M. (2015). Accuracy of teachers' judgments of students' subjective well-being. Learning and Individual Differences, 43, 226-232.

Vanlommel, K. (2018). Opening the black box of teacher judgement: the interplay of rational and intuitive processes. PhD diss., University of Antwerp.

Walker, H. M., Marquez, B., Yeaton, P., Pennefather, J., Forness, S. R., \& Vincent, C. G. (2015). Teacher judgment in assessing students' social behavior within a response-to-intervention framework: Using what teachers know. Education and Treatment of Children, 38(3), 363-382.

Westphal, A., Becker, M., Vock, M., Maaz, K., Neumann, M., \& McElvany, N. (2016). The link between teacher-assigned grades and classroom socioeconomic composition: The role of classroom behavior, motivation, and teacher characteristics. Contemporary Educational Psychology, 46, 218-227.

Woodruff, D. J., \& Ziomek, R. L. (2004). High school grade inflation from 1991 to 2003 (Research Report Series 2004-04). Iowa City, IA: ACT.

Zhu, M., Urhahne, D., \& Rubie-Davies, C. M. (2018). The longitudinal effects of teacher judgement and different teacher treatment on students' academic outcomes. Educational Psychology, 38(5), 648-668.

\section{Appendix}

\section{Read the text and choose the right answer.}

Towards the end of the 19th century, the disease known as beriberi (in Singhalese "I cannot"), with characteristic symptoms ranging from weakness to paralysis, spread dramatically through Dutch East Indies (presentday Indonesia). The Dutch government, concerned that there were hardly any slaves left on the plantations, set up a special committee. Christian Eijkman (1858-1930), a physician from the state prison in Batavia (presentday Jakarta) was among its members. One beautiful day, Dr. Eijkman was enjoying the view from the window of his official apartment overlooking the prison courtyard. His mind full of the cursed beriberi, he watched the hens pecking around the yard. He was intrigued by their strange movements and postures; somehow, they reminded him of the sick inmates... It turned out that the hens were, through the kitchen garbage, eating basically the same diet as the inmates: mostly rice. Specifically, they were eating husked rice. The husks were removed because a product processed in that way looks better and as a result was more profitable.

The suspicious Eijkman only needed to ask the "competitors" a few questions and everything was clear. Jails where the inmates consumed only husked rice had high numbers of beriberi patients, while in the jails where the managers economized and fed their inmates cheap rice that had not been husked, the disease was almost nonexistent. 
In 1897, Eijkman published his discovery. Despite its significance, there was almost no response. At that time, nutrition science was dominated by caloric assessments of nutrients, while the causes of diseases were decided by young and ambitious bacteriology. The idea that a mere deficiency in some trace element in the diet could cause a serious disease or even death simply seemed ridiculous.

However, in 1911, Eijkman's work was discovered by a young biochemist of Polish origin named Kazimierz Funk (1884-1967) who was living in London. He first tested Eijkman's conclusions on pigeons. He then got a kilo of rice husks and laboriously prepared six grams of white powder from them. This powder, even in milligram measurements, reliably cured beriberi. Funk called it vitamin B; vita means "life" in Latin and amin was for the amin group that the powder contained. He used letter " $B$ " to avoid confusion with a substance of a similar category that had been discovered shortly before in milk by Funk's colleague Frederick Hopkins (1861-1947) who called it growth factor A (today known as vitamin A). It is clear that Funk's name was widely accepted, even though the amin group after which it was named is, out of all the thirteen vitamins that are known, only contained in "his" vitamin (it is at present known as vitamin $B_{1}$ ). Eijkman and Hopkins were awarded the Nobel Prize in 1929.

(Houdek F., Tưma J.: Objevy a vynálezy tisicileti [Discoveries and Inventions of the Millennium], Nakladatelstvi Lidové noviny 2002, p. 233)

\section{Which of the following statements is directly contradicted in the text above?}

- Christian Eijkman died in prison in Batavia.

- The beriberi disease can be cured with six grams of a special white powder.

- Kazimierz Funk was later awarded the Nobel Prize.

- The beriberi disease was widespread in all prisons of the Dutch East Indies.

- Vitamin $B_{1}$ can be found in particular in husked rice; rice that has not been husked does not contain it at all. 


\section{Authors:}

Mgr. Anna Drexlerová

Masaryk University

Faculty of Arts

Department of Educational Sciences

Arne Nováka 1

60200 Brno

Czech Republic

Email:a.drexlerova@mail.muni.cz

doc. Mgr. Klára Šed’ová, Ph.D.

Masaryk University

Faculty of Arts

Department of Educational Sciences

Arne Nováka 1

60200 Brno

Czech Republic

Email:ksedova@phil.muni.cz

Mgr. Martin Sedláček, Ph.D.

Masaryk University

Faculty of Arts

Department of Educational Sciences

Arne Nováka 1

60200 Brno

Czech Republic

Email:msedlace@phil.muni.cz 